\title{
Chronic encapsulated intracerebral hematoma: a rare complication after stereotactic radiosurgery for cerebral arteriovenous malformation
}

\author{
Satoru Takeuchi • Yoshio Takasato
}

Received: 20 October 2010 /Accepted: 25 October 2010 /Published online: 5 November 2010

(C) Springer-Verlag 2010

We read with great interest the article entitled "Operative intervention for delayed symptomatic radionecrotic masses developing following stereotactic radiosurgery for cerebral arteriovenous malformations-case analysis and literature review" by Foroughi et al. [1] in the May 2010 issue of this journal. The authors presented two cases of delayed masses that had developed following stereotactic radiosurgery (SRS) for the treatment of cerebral arteriovenous malformations (AVMs) and discussed the relevant literature. They pointed out that some cases had presented with hemorrhage in the cystic cavity. We would like to add a comment regarding this point.

Chronic encapsulated intracerebral hematoma (CEIH) is a rare cerebrovascular disease that behaves as a slowly expanding lesion with a gradual onset [2]. We previously reported a case of delayed CEIH that developed after SRS for a cerebral AVM, which was treated by a single

\footnotetext{
S. Takeuchi $(\bowtie)$

Department of Neurosurgery,

National Defense Medical College,

3-2 Namiki,

Tokorozawa, Saitama 359-8513, Japan

e-mail: s.takeuchi@room.ocn.ne.jp

Y. Takasato

Department of Neurosurgery,

National Hospital Organization Disaster Medical Center,

Tokyo, Japan
}

aspiration following the placement of a reservoir [3]. Furthermore, we experienced a similar case of a delayed mass that developed after SRS for an AVM. This patient underwent surgical excision and was diagnosed as CEIH by a pathological method. We suppose that SRS for an AVM can cause the formation of CEIH. Based on our experiences, it is suggested that some delayed masses with hemorrhage after SRS for an AVM may be CEIH.

Conflicts of interest None.

\section{References}

1. Foroughi M, Kemeny AA, Lehecka M, Wons J, Kajdi L, Hatfield R, Marks S (2010) Operative intervention for delayed symptomatic radionecrotic masses developing following stereotactic radiosurgery for cerebral arteriovenous malformations-case analysis and literature review. Acta Neurochir (Wien) 152:803-815

2. Fiumara E, Gambacorta M, D'Angelo V, Ferrara M, Corona C (1989) Chronic encapsulated intracerebral haematoma: pathogenetic and diagnostic considerations. J Neurol Neurosurg Psychiatry 52:1296-1299

3. Takeuchi S, Takasato $\mathrm{Y}$, Masaoka H, Hayakawa T, Otani N, Yoshino Y, Yatsushige H, Sugawara T (2009) Development of chronic encapsulated intracerebral hematoma after radiosurgery for a cerebral arteriovenous malformation. Acta Neurochir (Wien) $151: 1513-1515$ 